\title{
Migration, Occupational Mobility, and Regional Escalators in Scotland
}

\author{
Maarten van Ham, ${ }^{1,2,3}$ Allan Findlay, ${ }^{4}$ David Manley, ${ }^{5}$ and Peteke Feijten ${ }^{6}$ \\ ${ }^{1}$ OTB Research Institute for the Built Environment, Delft University of Technology, P.O. Box 5030, 2600 GA Delft, The Netherlands \\ ${ }^{2}$ School of Geography \& Geosciences, University of St Andrews, St Andrews, Fife KY16 9AJ, UK \\ ${ }^{3}$ IZA, 53113 Bonn, Germany \\ ${ }^{4}$ Department of Geography and Sustainable Development, ESRC Centre for Population Change, University of St Andrews, \\ Irvine Building, North Street, St Andrews KY16 9AL, UK \\ ${ }^{5}$ School of Geographical Sciences, University of Bristol, University Road, Clifton, Bristol BS8 1SS, UK \\ ${ }^{6}$ The Netherlands Institute for Social Research, P.O. Box 16164, 2500 BD The Hague, The Netherlands
}

Correspondence should be addressed to Maarten van Ham, m.vanham@tudelft.nl

Received 8 June 2012; Revised 3 December 2012; Accepted 4 December 2012

Academic Editor: César Ducruet

Copyright ( $) 2012$ Maarten van Ham et al. This is an open access article distributed under the Creative Commons Attribution License, which permits unrestricted use, distribution, and reproduction in any medium, provided the original work is properly cited.

\begin{abstract}
This paper seeks to unpick the complex relationship between an individual's migration behaviour, their place of residence, and their occupational performance in the Scottish labour market between 1991 and 2001 . We investigate whether Edinburgh has emerged as an occupational escalator region and whether individuals moving there experience more rapid upward occupational mobility than those living and moving elsewhere. Using country of birth, we also control for an individual's propensity to make long distance moves during earlier periods of their life course. Using data from the Scottish Longitudinal Study, linking 1991 and 2001 individual census records, and logistic regressions, we show that those who migrate over long distances within or to Scotland are most likely to achieve upward occupational mobility. We also found that Edinburgh is by far the most important regional escalator in Scotland; those moving to Edinburgh are the most likely to experience upward occupational mobility from low to high occupational status jobs. This is an important finding as most of the literature on escalator regions focuses on international mega cities.
\end{abstract}

\section{Introduction}

Although Fielding [1-3] was not the first to hypothesise that a stay in large metropolitan regions is beneficial to labour careers, he was the first to frame this idea in dynamic terms when he coined the term "escalator region." The escalator hypothesis posits that escalator regions offer labour market opportunities that other regions do not offer and as a result propel the careers of in-migrants at a faster rate than other regions [4]. In the three-stage model of the escalator region, young people move to these regions, then advance their careers, and step-off the escalator later in life when they move out of the region. Fielding tested, and broadly confirmed, his hypothesis for London's extended metro region using data from 1971 and 1991.

Since the conception of the escalator region hypothesis by Fielding, many studies have followed (see [5] for an excellent overview of the literature), and all of them confirm that a stay in a large metropolitan region has positive effects on careers. There is less clarity on the causal mechanism underlying this finding, and the escalator concept has also received criticism (see also $[4,6])$. Does the escalator region offer exceptional opportunities, or do in-migrants have certain characteristics which cause them to do better than others? In the first case, you would expect that also those who were born and stay in such regions benefit. Gordon [7] recently investigated the relation between ambition and the escalator region role of high-order metropolitan regions (the London metro area) and found that only the most ambitious gains from stays in such regions.

Most studies testing the escalator region hypothesis have followed Fielding in focussing on large high-order metropolitan regions. Such regions are thought to have a national (and to some extent international) role in occupational 
mobility. There are, however, large and persistent regional differences in opportunities for occupational mobility between (and within) regions within countries caused by differential economic and political circumstances. In this study, we argue that also regional capitals might function as escalators for occupational mobility on both a regional and a national level. This idea is strengthened by recent work which shows that also relatively young people move out of the south east of England [5].

In this study, we investigate the existence of regional escalator effects on occupational mobility in Scotland. Scotland makes an interesting case in the regional context of devolved government. Edinburgh, the Scottish political capital, has achieved greater command and control functions both relative to the rest of Scotland and to the UK core economic region of the south east of England. We are specifically interested in two dimensions of occupational mobility. The first is a regional one. We seek to identify if there are regional variations in occupational mobility within Scotland. A number of powerful forces have produced potentially uneven opportunities for occupational advancement in Scotland, arising from large regional disparities in access to job opportunities. Edinburgh, as capital of a devolved nation, hub for financial service activities, and regional head office location for many public sector bodies, it seems to boast many of the characteristics that one would expect to find in a region offering good opportunities for rapid occupational mobility. One would certainly anticipate that this would be true compared with most other urban areas in Scotland, and if regional escalator effects exist, they should be apparent in the case of Edinburgh.

The second dimension of occupational mobility is its relationship to migration. We pay particular attention to the labour force experiences of individuals who are willing to move over long distances between employers. The literature suggests that this form of migration is beneficial for occupational advancement because it can facilitate access to better job opportunities [8]. In addition to long distance mobility within Scotland, we also use country of birth to explore an added dimension where individuals who have previously made a long distance move in their life course, either from England or Wales, or from outside Great Britain into Scotland, are more likely to experience upward occupational mobility, especially in comparison to their Scottish counterparts who have not made interregional or international moves.

This is the first systematic longitudinal study for Scotland that examines the effects of access to job opportunities, short and long distance migration, and a range of independent socioeconomic variables on upward (and downward) occupational mobility. We are especially interested in the differences in labour market experiences between individuals moving over long distances into the major urban centres of Scotland such as Edinburgh and Glasgow in comparison to individuals who have not migrated. This is also one of the first papers to draw evidence from the recently constructed and very powerful Scottish Longitudinal Study (SLS) which links individual records from the 1991 and 2001 Scottish censuses with a sample of $5.3 \%$ of the Scottish population [9].
We study social mobility by comparing the socioeconomic position - based on occupations_-of SLS members in 1991 and 2001.

\section{Literature Review}

2.1. Labour Markets and Escalator Regions. Ever since Blau and Duncan [10], it has been recognized that an individual's willingness to migrate is a significant factor in their occupational achievement. In their book "The American Occupational Structure", Blau and Duncan argued that there are differences in the opportunity structures of different labour markets and that migration is an important instrument to access other labour markets with better opportunities. In the last decade, there has been a substantial increase in disparities between regional labour markets within countries, but there has also been a major growth in the disparities between national labour markets $[11,12]$. Thus, the occupational mobility opportunities for individuals willing to migrate to other labour markets, especially for those originating from a labour market with restricted opportunities, are more substantial now than at any point in the past.

The economic specialisation that followed the reorganisation of national production systems, since the 1970s, to serve global markets (in what Massey [13] described as the new international division of labour), led to the redistribution of jobs socially and the relocation of jobs geographically $[14,15]$. In most advanced economies, this not only meant a greater concentration of jobs in the service sector, especially white collar, managerial, and professional jobs, but it also produced increasingly uneven regional distributions with concentrations in core economic regions of countries and at an international scale in global cities and city regions [16]. These profound changes affected opportunities for occupational mobility in western economies. In most countries, there is an increasingly uneven spatial pattern of job opportunities and opportunities for occupational mobility [8]. As a result, we have an appreciation that labour markets must not be treated as homogeneous and impermeable spaces. In contrast, labour markets exhibit a highly uneven geography of development which highlights their heterogeneous nature and the large intra- and intermarket differences that exist both within and between them [13]. Within the labour market literature, the spatial nature of relationships has been well documented (e.g., see $[8,17]$ ).

It is well known that job-related migration, especially for the skilled and highly skilled, is associated with upward occupational mobility [8] with those with the highest levels of human capital being the most likely to move longer distances [18]. This apparently simple formulation remains vital in understanding why some people will advance more rapidly than others in occupational terms, since it follows that those with credentials and a willingness to move will achieve occupational mobility more quickly than those who are either rooted in place or facing personal constraints on their mobility. Married couples with children and home owners provide obvious examples here [19-21]. It is important to note here that it is likely that people who are motivated 
to do better in their careers are also more likely to accept jobs outside their own labour market and therefore requiring longer distance moves. If this is the case, one could question to what extent a positive association between long distance mobility and occupational achievement can be interpreted as being the effect of the former on the latter [22]. However, conceptually, long distance mobility is a cost which is instrumental in career advancement. Long distance mobility is therefore not the cause of career advancement, but an instrument that leads to career advancement. Obviously, more motivated workers will more often use this instrument, but this does not change the instrumental nature of long distance mobility, and one may still state that long distance mobility helped to advance the careers of these motivated workers [22].

The relationship between spatial and occupational mobility and urban form has given rise to the concept of the escalator region $[1,16]$. The concept draws clearly on the metaphor of an escalator as a means of moving both forward and upward and when applied in a geographical context suggests that some regions not only provide more opportunities for occupational mobility, but that this will produce patterns of interregional migration towards these regions by those seeking more rapid advancement. Fielding [1-3] argued that a higher density of job opportunities in an escalator region also made it possible for people living there to earn higher salaries and to gain occupational promotion more quickly than others. Champion [23] found that many upwardly mobile people leave escalator regions at some point later in their career, returning to regional labour markets (see also [5]). A refinement worth noting is that empirical research shows that there are many routes to upward mobility and that only a minority of migrants moving into the UK's main escalator region are rewarded by promotion at the time of their initial move and that most receive the reward for their move only after some time [24]. In this light, Gordon [7] recently found for the UK that only those who are most ambitious gain from residence in the extended London region, so living in London is not a sufficient pre-requisite to be upwardly mobile.

There are two contexts within which the escalator concept holds particular promise. The first context involves research that specifically studies occupational mobility in global cities as opposed to within the heterogeneously diverse spatial container of the nation state. There has been remarkably little empirical testing of how unevenness in occupational mobility operates in global city regions, where very diverse ethnic groups are brought together in sometimes extremely polarised labour market conditions. These cities, on the one hand, involve elite mobility involving the social networks that make up the so-called transnational capitalist class [25]. On the other hand, people of diverse origins are drawn to work in the low-wage service economy of global cities often involving the downward mobility of well-qualified people who are glad to accept wages that exceed those in countries of origin and involving youthful cohorts of mobile people seeking an entry point that allows them a temporary experience of living in the global city $[26,27]$.
The second context that remains understudied is the nature of occupational mobility in regional economies. In most so-called peripheral areas, it is easy to identify specific cities that stand out as different from other towns and settlements because they function as regional command and control centres for the wider regional and sometimes global economy. There are at least five ways in which these cities have been shown to be distinctive in relation to the spatial and occupational mobility of their citizens [28]. First, they attract new service-class migrants [29] from the core of the economy whose moves are channelled within the "network of flows" that sustains contemporary capitalism [30]. Second, these cities have a disproportionately high share of mobile workers from the new service-class relative to the regional economy as a whole. Third, regional cities attract these workers not just from the core economic region of the national economy but also from regional and international command and control centres in other countries. Fourth, these cities often exhibit a functional disconnection between the patterns of occupational mobility found amongst the local population employed in the service sector and the circuits of movement found amongst new service-class migrants from outside the region. The glass ceiling on upward mobility of some employees applies not only to long-established local people but, as noted earlier, also to second generation members of visible ethnic minorities. Fifth, these regional centres require the mobility of skilled workers to be sustained for the wider regional economy to remain healthy. Thus, not only are they sites of inward and upward mobility, but they are also sites of upward and outward moves. The last feature is not surprising since it has been found that global cities also exhibit outward movement of upwardly mobile, people, and this involves not only onward moves to other global cities, but also some significant return migration of highly skilled people seeking to relocate to the regional control and command centres found in their region of origin [24].

\subsection{From Theoretical Context to Research Questions. This} literature review has provided evidence of the diversity of economic and social factors that contribute to the continued unevenness of occupational mobility in western societies. As has been argued, these social processes are deeply spatially embedded and produce social landscapes where opportunities for social mobility are not merely uneven but are structured in such a way that they accentuate inequalities over time. This has been argued to be true not only in the core economic regions of contemporary world capitalism, notably in the regions of world cities, but also in regional centres where spaces of flows reproduce inequalities through the movement of workers in the new service class.

This paper sets out to examine two particular features. Firstly, we ask if there is any evidence that Edinburgh, the Scottish political capital, could be becoming an escalator region within Scotland, at a time when it has achieved greater command and control functions both relative to the UK core economic region of the south east of England and relative to the rest of Scotland. If this were to be the case, one might expect to see evidence of the Edinburgh labour market 
offering opportunities for more rapid occupational mobility than other parts of Scotland. Similarly, an escalator region would be expected to assist with the maintenance of social position for individuals already in higher occupational positions in comparison with other regions within Scotland. Within this question, we also seek to determine if Scotland's other major city, Glasgow, also exhibits any evidence of being an escalator region within the Scottish context.

Secondly, we seek to link the mobility experiences of individuals and their labour market performance to assess if there is evidence in Scotland that individuals willing to migrate over long distances are more likely to experience better labour market outcomes than individuals who do not migrate, or only migrate over short distances. In line with previous labour market literature, we would expect to see that individuals who migrate over longer distances are more likely to experience upward occupational mobility. By including information about the country of birth, either from England or Wales, or from outside Great Britain, we also enable the identification of individuals who have made long distance moves into Scotland at some point in the past, even if their current level of residential mobility is relatively low.

\section{Data and Methods}

We use data from the Scottish Longitudinal Study (SLS), which contains linked 1991 and 2001 census records for approximately 274,000 people, around $5.3 \%$ of the Scottish population [9]. The longitudinal nature of the data allows us to link 1991 individual and locational characteristics to 2001 outcomes. The research population included all individuals present in Scotland who were employed in both 1991 and 2001. Individuals without a job in either 1991 or 2001 were omitted from the study, as were those who were younger than 15 or older than 55 in 1991.

The main interest of this study lies in modelling individual occupational mobility between 1991 and 2001. To determine whether someone experienced occupational mobility, we compared their socioeconomic position in 1991 and 2001. Socioeconomic position is derived from the National Statistics Socioeconomic Classification (NS-SEC), which provides an indication of socioeconomic position based on a combination of people's current or last main job, the size of the establishment where they work, and their employment status (whether an employer, self-employed, a manager, a supervisor, or an employee). The NS-SEC is constructed from the Standard Occupational Classification 2000 (SOC2000) (Office for National Statistics, [31, 32]) and has 8 broad categories: (1) higher managerial occupations and higher professional occupations; (2) lower professional and higher technical occupations; (3) intermediate occupations; (4) employers in small organisations and own account workers; (5) lower supervisory and technical occupations; (6) semiroutine occupations; (7) routine occupations; (8) never worked and long-term unemployed.

Based on the 8 different categories, it is possible to create an 8 by 8 matrix with possible transitions between occupational status groups. Modelling this full matrix is problematic due to both floor and ceiling effects. Floor effects occur for those in the lowest occupational status category as by default they can only remain where they are, or move up. Ceiling effects occur for those in the highest occupational status category as they can only stay where they are, or move down. When modelling the full matrix, counterintuitive results show up, such as that those in social housing are the most likely to improve their occupational status. This is purely an artefact of a floor effect; those in social housing are often in the lowest occupational status category and therefore can only move up or stay where they are.

Since we are really interested in who moves up and who moves down, we decided to collapse the previous categories into two categories: (A) high occupational position consisting of NS-SEC categories 1 and 2; (B) low occupational position consisting of NS-SEC categories 3, 5, 6, and 7. We excluded the self-employed in NS-SEC category 4 as this is a very heterogeneous group containing, for example, selfemployed brick layers along with self-employed book editors or publishers. NS-SEC category 8 (the long-term unemployed and those who had never worked) was also excluded. Based on this, we constructed two dependent variables. The first dependent variable measures whether or not those in the low occupational status group (NS-SEC 3,5,6, or 7) in 1991 "moved up" to the high occupational status group (NS-SEC 1 or 2) in 2001. The outcome is coded into a dummy variable scoring 0 for those individuals who have remained in the low status group and 1 identifying those who have moved into the high status group. The second dependent variable measures whether those in the high status group maintained their high occupational status. It is coded into a dummy variable with score 0 for those who experienced downward mobility into the low status group, and 1 for those who remained in the high status group. By concentrating on transitions between the low and high occupational status groups, we reduce the complexity of our data and avoid floor and ceiling effects, accepting that we could also lose some detail in our analyses. See Table 1 for summary statistics of the dependent and independent variables. Since the dependent variables are binary, we have used standard logistic regression models.

The most important set of independent variables in the analysis combines place of residence in 2001 and moving distance. We classified places of residence based on access to job opportunities, using Council Area boundaries combined with the Urban/Rural classification developed by the Scottish Government from the 1991 census [33]. The Urban/Rural classification is based on access to concentrations of population, which we use as a proxy for access to job opportunities [34]. We categorised places of residence by job access in five categories: Edinburgh (individuals living in Council Area of Edinburgh and in an area with a population of over 100,000); Glasgow (individuals living in Council Area of Glasgow and in an area with a population of over 100,000); other cities (areas with a population of over 100,000 people but not within the Council Areas of Edinburgh or Glasgow), which include Aberdeen, Dundee, and Inverness; areas with medium job access (areas coded as being either accessible towns or accessible rural areas where accessibility is defined 
TABLE 1: Variable summary statistics.

\begin{tabular}{|c|c|c|}
\hline & $\begin{array}{l}\text { Low occupational status 1991, } \\
\qquad N=36,330\end{array}$ & $\begin{array}{l}\text { High occupational status 1991, } \\
\qquad N=15,024\end{array}$ \\
\hline \multicolumn{3}{|l|}{ Country of birth } \\
\hline Scotland (reference) & 33,809 & 12,833 \\
\hline England and Wales & 1,909 & 1,657 \\
\hline Outside Great Britain & 612 & 534 \\
\hline \multicolumn{3}{|c|}{ Place of residence 2001 by mobility between 1991 and 2001} \\
\hline Glasgow no move & 1,076 & 383 \\
\hline Glasgow short move & 1,641 & 643 \\
\hline Glasgow long move & 64 & 41 \\
\hline Edinburgh no move & 1,046 & 744 \\
\hline Edinburgh short move & 1,361 & 861 \\
\hline Edinburgh long move & 119 & 93 \\
\hline Cities no move & 7,617 & 3,074 \\
\hline Cities short move & 11,214 & 3,987 \\
\hline Cities long move & 660 & 466 \\
\hline Medium job access no move & 3,398 & 1,458 \\
\hline Medium job access short move & 4,898 & 2,058 \\
\hline Medium job access long move & 513 & 431 \\
\hline Low job access no move & 1,068 & 205 \\
\hline Low job access short move & 1,358 & 391 \\
\hline Low job access long move & 297 & 189 \\
\hline Female $($ reference $=$ male $)$ & 18,041 & 6,884 \\
\hline Age 1991 (average years) & 34.74 & 36.97 \\
\hline Ethnic minority (reference $=$ not ethnic minority) & 126 & 90 \\
\hline \multicolumn{3}{|l|}{ Change in presence of children } \\
\hline 1991/2001 no children (reference) & 8,754 & 5,032 \\
\hline 1991 no child/2001 child & 5,890 & 2,527 \\
\hline Children 1991/2001 & 13,027 & 4,016 \\
\hline 1991 child/2001 no child & 8,659 & 3,450 \\
\hline \multicolumn{3}{|l|}{ Change in household } \\
\hline Couple 1991 and 2001 (reference) & 20,956 & 10,304 \\
\hline Couple 1991, single 2001 & 3,213 & 850 \\
\hline Single 1991 and 2001 & 5,722 & 1,921 \\
\hline Single 1991, couple 2001 & 6,439 & 1,950 \\
\hline \multicolumn{3}{|l|}{ Change in health } \\
\hline Not ill 1991 and 2001 (reference) & 33,108 & 13,846 \\
\hline Ill in 1991 and 2001 & 260 & 96 \\
\hline Ill 1991 only & 630 & 218 \\
\hline Ill 2001 only & 2,332 & 864 \\
\hline \multicolumn{3}{|l|}{ Post-18 qualifications 1991} \\
\hline None (reference) & 34,276 & 6,021 \\
\hline Vocational & 1,412 & 4,879 \\
\hline Degree or higher & 642 & 4,124 \\
\hline \multicolumn{3}{|l|}{ Tenure 1991} \\
\hline Owner occupation (reference) & 22,847 & 12,769 \\
\hline Social renting & 11,465 & 1,400 \\
\hline Private renting & 2,018 & 855 \\
\hline
\end{tabular}

Source: calculations done by the authors using data from the SLS. 
as 30 minutes or less drive time from a settlement with a population of 10,000 or greater) typically including places such as Stirling and Perth as well as some of the semirural areas in close to larger settlements and cities; areas with low job access (areas coded as being either inaccessible towns or inaccessible rural areas, where inaccessibility is defined as more than a 30-minute drive time from a settlement with a population of 10,000 or greater) including much of the Highlands along with some of the Scottish Border areas. Figure 1 shows the spatial distribution of the area classifications based on access to employment opportunities. It is clear from the map that the vast majority of areas with good job access are located in and around Edinburgh, Glasgow, and the central belt that connects the two cities.

We also measured whether people moved between the 1991 and the 2001 census, and people were categorised into three categories: (1) nonmovers; (2) short distance movers (less than $35 \mathrm{~km}$ ); (3) long distance movers (more than $35 \mathrm{~km}$ ). We decided on 35 kilometres as a threshold for short distance moves because when moving over less than $35 \mathrm{~km}$, the potential activity space of individuals remains relatively similar, with other words, they can visit the same friends, shops, schools, and so forth. on a daily basis (see also [19, 35]). We then combined the area classification variable with the mover status variable into one. This variable allows us to distinguish between people moving over short and long distances between various types of regional labour markets. The inclusion of Edinburgh and Glasgow as distinct entities from the other cities in Scotland allows an assessment of whether these two cities are acting as escalator regions.

To supplement the measure of migration between the two census periods, we also included country of birth as a means to measure life course mobility. This has a dual purpose, as it enables the distinction of individuals in the Scottish labour market who may have made long distance moves (either from other parts of the UK or from other countries) in the past into Scotland even when their current level of mobility, as measured between the 1991 and 2001 censuses, was low. The second purpose of the country of birth variable is that it enables the recognition of the diversity of the Scottish population to be featured in the model.

We included various control variables in our models which can be expected to be related to social mobility: gender; age; ethnicity; change in the presence of children between 1991 and 2001; change in household composition between 1991 and 2001; change in health status between 1991 and 2001 based on long-term limiting illnesses; 1991 postcompulsory (post-18) educational qualifications in three groups; 1991 housing tenure. Descriptions for all these variables can be found in Table 1 .

\section{Results}

4.1. Spatially Uneven Occupational Mobility. Table 2 shows the relationship between place of residence in 2001 and occupational mobility between 1991 and 2001 for three categories: those born in Scotland; those born in England and Wales; those born outside Great Britain. The table shows
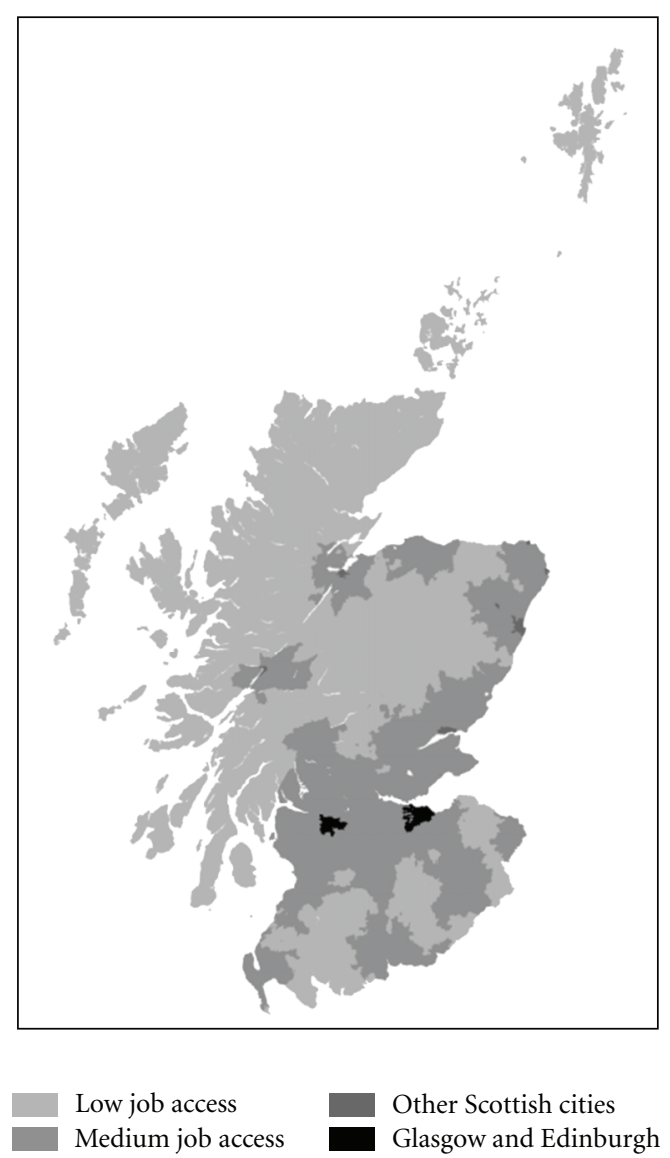

FIGURE 1: Map of Scotland showing area classifications based on access to employment opportunities. Source: 2001 census output area boundaries. Crown copyright 2003. Crown copyright material is reproduced with the permission of the Controller of HMSO.

occupational mobility between low and high occupational status groups. The results show a complex pattern of occupational mobility in Scotland. For individuals born in Scotland, by far the best place to live is Edinburgh as individuals living there are the most likely to achieve upward occupational mobility between 1991 and 2001. Once the Scots have achieved a high occupational status, they are most likely to keep it when living in Glasgow and Edinburgh. Also, for the English and Welsh born, those living in Edinburgh are by far the most likely to achieve upward occupational mobility or maintaining a high position compared to individuals living elsewhere. For those born outside Great Britain, the pattern is much more complicated (partly due to low numbers in various categories). Individuals living in one of the other cities (Aberdeen, Dundee, or Inverness) are the most likely to experience upward social mobility, compared to places with medium job access and Edinburgh. In terms of maintaining a high occupational position, those individuals from outside Great Britain living in the areas with medium job access within 30 minutes travel time are the most likely to do well, compared to individuals living elsewhere. It should be noted that this includes a large proportion of the suburban area between Glasgow and Edinburgh which houses a large 
TABLE 2: Mobility between high and low occupational status groups (1991-2001) by place of residence in 2001 and country of birth.

\begin{tabular}{|c|c|c|c|c|c|}
\hline & Population born in Scotland & & & pationa & group \\
\hline & & & $\begin{array}{l}\text { High } \\
(\%)\end{array}$ & $\begin{array}{l}\text { Low } \\
(\%)\end{array}$ & $N$ \\
\hline Glasgow & & High & 85.06 & 14.94 & 1,044 \\
\hline & & Low & 23.81 & 76.19 & 2,670 \\
\hline Edinburgh & & High & 84.50 & 15.50 & 1,399 \\
\hline & & Low & 29.94 & 70.06 & 2,308 \\
\hline Other city & 1991 occupation status group & High & 81.77 & 18.23 & 6,877 \\
\hline & 1991 occupation status group & Low & 22.84 & 77.16 & 18,341 \\
\hline Medium iob access & & High & 82.05 & 17.95 & 3,153 \\
\hline Medim jov access & & Low & 21.75 & 78.25 & 8,234 \\
\hline Low iob access & & High & 80.03 & 19.97 & 836 \\
\hline Low joo access & & Low & 17.70 & 82.30 & 2,469 \\
\hline & $\begin{array}{l}\text { Population born in England and } \\
\text { Wales }\end{array}$ & & & pation & group \\
\hline & & & $\begin{array}{l}\text { High } \\
(\%)\end{array}$ & $\begin{array}{l}\text { Low } \\
(\%)\end{array}$ & $N$ \\
\hline Glasgow & & High & 89.70 & 10.30 & 68 \\
\hline & & Low & 29.42 & 70.58 & 68 \\
\hline Edinburgh & & High & 90.65 & 9.35 & 289 \\
\hline & & Low & 46.79 & 53.21 & 156 \\
\hline Other city & 1991 occunation status oroun & High & 84.29 & 15.71 & 592 \\
\hline Utrer cily & 1991 occupation status group & Low & 30.28 & 69.72 & 875 \\
\hline & & High & 87.31 & 12.69 & 607 \\
\hline Medium Job Access & & Low & 28.70 & 71.30 & 662 \\
\hline Low Job Access & & High & 84.87 & 15.13 & 152 \\
\hline LOW jOD ACcess & & Low & 23.87 & 76.13 & 222 \\
\hline & Population born outside GB & & 2 & pation & group \\
\hline & & & $\begin{array}{l}\text { High } \\
(\%)\end{array}$ & $\begin{array}{l}\text { Low } \\
(\%)\end{array}$ & $N$ \\
\hline Glasgow & & High & 90.39 & 9.61 & 52 \\
\hline Giasgow & & Low & 20.00 & 80.00 & 55 \\
\hline Edinburoh & & High & 90.82 & 9.18 & 109 \\
\hline Edilvurgit & & Low & 30.26 & 69.74 & 76 \\
\hline & & High & 87.99 & 12.01 & 208 \\
\hline Uther city & 1991 occupation status group & Low & 50.00 & 50.00 & 170 \\
\hline Medium job access & & High & 93.44 & 6.56 & 168 \\
\hline Niedium joo access & & Low & 37.42 & 62.58 & 155 \\
\hline Lov & & High & 91.17 & 8.83 & 34 \\
\hline LOW Jou decess & & Low & 20.84 & 79.16 & 48 \\
\hline
\end{tabular}

Source: calculations done by the authors using data from the SLS.

number of commuters working in the two major urban centres.

Because of the data disclosure policy of the SLS, we were not allowed to combine place of residence and migration between 1991 and 2001 in one table. We have therefore requested a separate table showing the relationship between spatial mobility status between 1991 and 2001 and occupational mobility between 1991 and 2001. Table 3 shows, as would be expected, that those individuals making long distance moves between 1991 and 2001 are the most likely to have experienced upward occupational mobility across all countries of birth. Those individuals making short distance moves between 1991 and 2001 are more likely to experience upward mobility than those making no moves between the two censuses. In terms of country of birth disaggregation, those born outside Scotland are more likely than those 
TABLE 3: Mobility between high and low occupational status groups (1991-2001) by spatial mobility status between 1991 and 2001 and country of birth.

\begin{tabular}{|c|c|c|c|c|c|}
\hline & \multirow{2}{*}{ Population born in Scotland } & & \multicolumn{3}{|c|}{2001 occupational status group group } \\
\hline & & & $\begin{array}{c}\text { High } \\
(\%)\end{array}$ & $\begin{array}{l}\text { Low } \\
(\%)\end{array}$ & $N$ \\
\hline \multirow{2}{*}{ No move } & \multirow{6}{*}{1991 occupation status group } & High & 82.11 & 17.89 & 1,058 \\
\hline & & Low & 17.46 & 82.54 & 2,659 \\
\hline \multirow{2}{*}{ Short distance move } & & High & 82.59 & 17.41 & 1,001 \\
\hline & & Low & 25.34 & 74.66 & 2,706 \\
\hline \multirow{4}{*}{ Long distance move } & & High & 85.68 & 14.32 & 11,096 \\
\hline & & Low & 37.14 & 62.86 & 14,122 \\
\hline & \multirow[t]{2}{*}{ Population born in England and Wales } & & \multicolumn{3}{|c|}{2001 occupational status group } \\
\hline & & & $\begin{array}{c}\text { High } \\
(\%)\end{array}$ & $\begin{array}{l}\text { Low } \\
(\%)\end{array}$ & $N$ \\
\hline \multirow{2}{*}{ No move } & \multirow{6}{*}{1991 occupation status group } & High & 86.42 & 13.58 & 1,805 \\
\hline & & Low & 25.88 & 74.12 & 1,909 \\
\hline \multirow{2}{*}{ Short distance move } & & High & 86.46 & 13.54 & 1,561 \\
\hline & & Low & 30.69 & 69.31 & 2,150 \\
\hline \multirow{4}{*}{ Long distance move } & & High & 87.80 & 12.20 & 14,677 \\
\hline & & Low & 48.56 & 51.44 & 10,541 \\
\hline & Population born outside GB & & \multicolumn{3}{|c|}{2001 occupational status group } \\
\hline & & & $\begin{array}{c}\text { High } \\
(\%)\end{array}$ & $\begin{array}{l}\text { Low } \\
(\%)\end{array}$ & $N$ \\
\hline \multirow{2}{*}{ No move } & \multirow{6}{*}{1991 occupation status group } & High & 89.78 & 10.22 & 1,708 \\
\hline & & Low & 20.56 & 79.44 & 2,006 \\
\hline \multirow{2}{*}{ Short distance move } & & High & 90.41 & 9.59 & 1,624 \\
\hline & & Low & 29.72 & 70.28 & 2,083 \\
\hline \multirow[t]{2}{*}{ Long distance move } & & High & 92.83 & 7.17 & 15,131 \\
\hline & & Low & 54.25 & 45.75 & 10,087 \\
\hline
\end{tabular}

Source: calculations done by the authors using data from the SLS.

born in either England, Wales, or in Scotland to experience upward mobility. The English and Welsh born are more likely than the Scottish born to experience upward mobility.

\subsection{Transitions from Low Status to High Status Occupations.} Table 4 presents the results from a series of logistic regression models estimating the probability of moving into the high status group between 1991 and 2001 for those who were in the low status group in 1991. The first model only includes country of birth dummies, and the results are similar to those found in Table 2; individuals born in England and Wales, or born outside Great Britain, are more likely to experience upward social mobility than those born in Scotland. This shows that individuals who have undertaken long distance moves before 1991 are more likely to experience occupational mobility later in life. This is probably due to the fact that these people are more motivated to advance their careers and are also more willing to move over longer distances (see also [22]). Model 2 includes a range of individual and household level control variables. The largest coefficients in the model are associated with qualifications. Individuals with post-18 qualifications (either vocational or a degree) are substantially more likely to experience upward mobility than those without post-18 qualifications. This result could be interpreted as people experiencing upward mobility primarily in relation to their talents, although it is important to remember that social class remains a key influence on educational attainment.

It is important to note that after including education and a wide range of other control variables explaining social mobility, the effect of country of birth still remains significant. This demonstrates that in comparison with the Scottish born, individuals born in England or Wales, or born outside Great Britain but living in Scotland in 1991, are more likely to experience upward social mobility. In terms of the initial hypotheses set out earlier, there is therefore some evidence that Scotland falls short of being entirely meritocratic. There appears to be an advantage for those who moved to Scotland from elsewhere. However, caution is necessary as selection effects might be (partly) responsible for our results. Those in- 


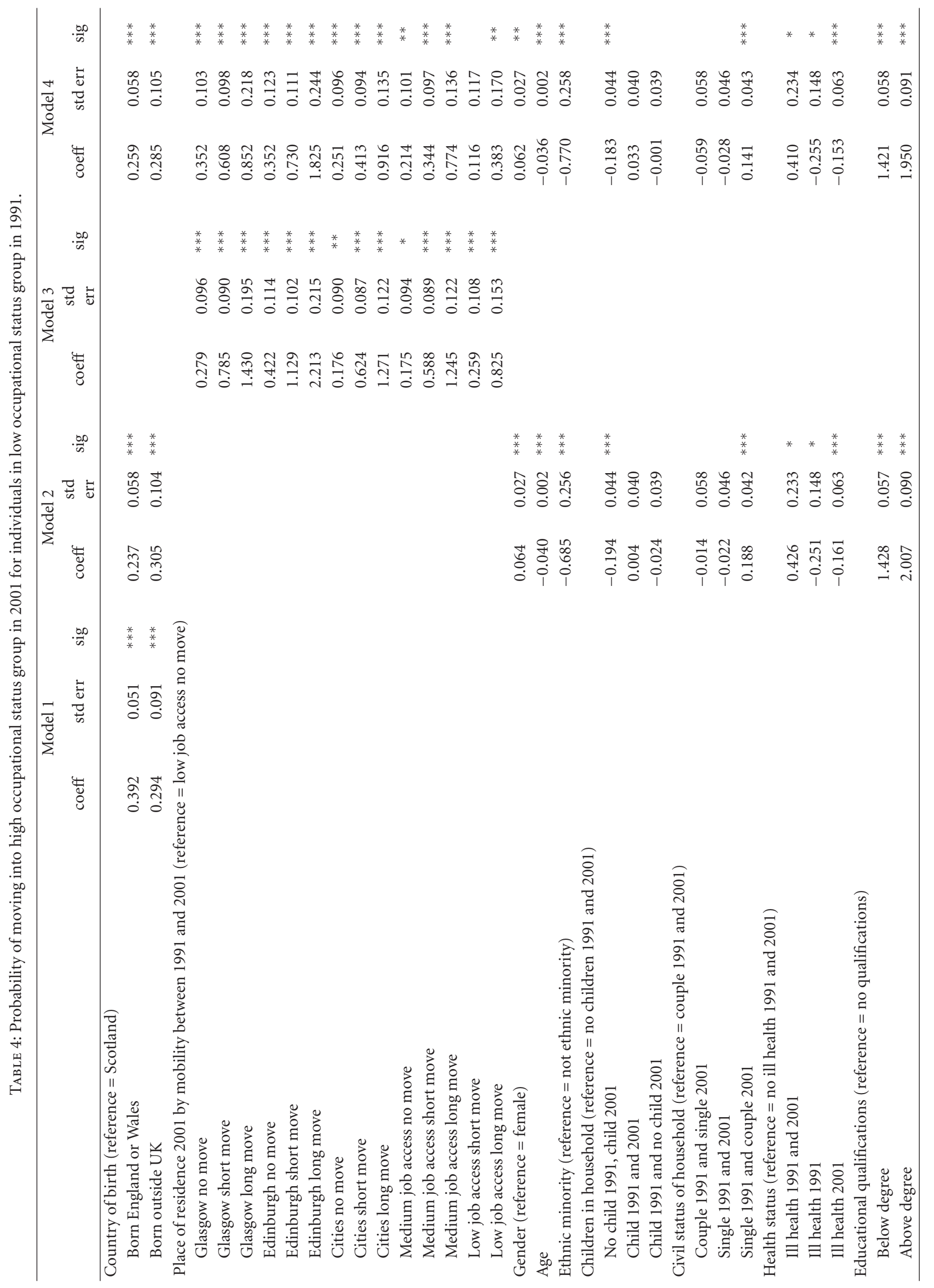




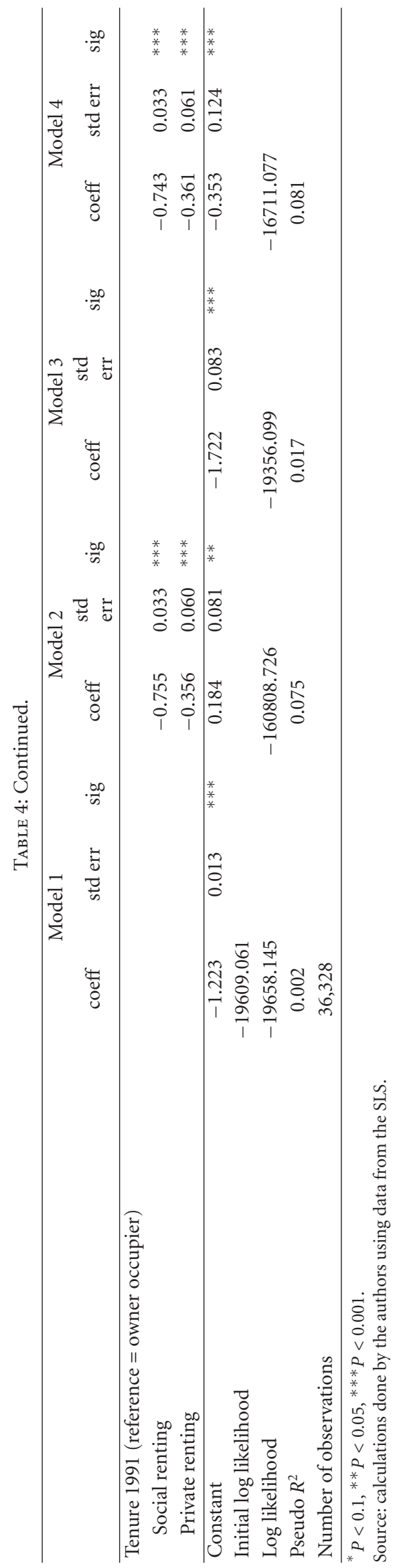




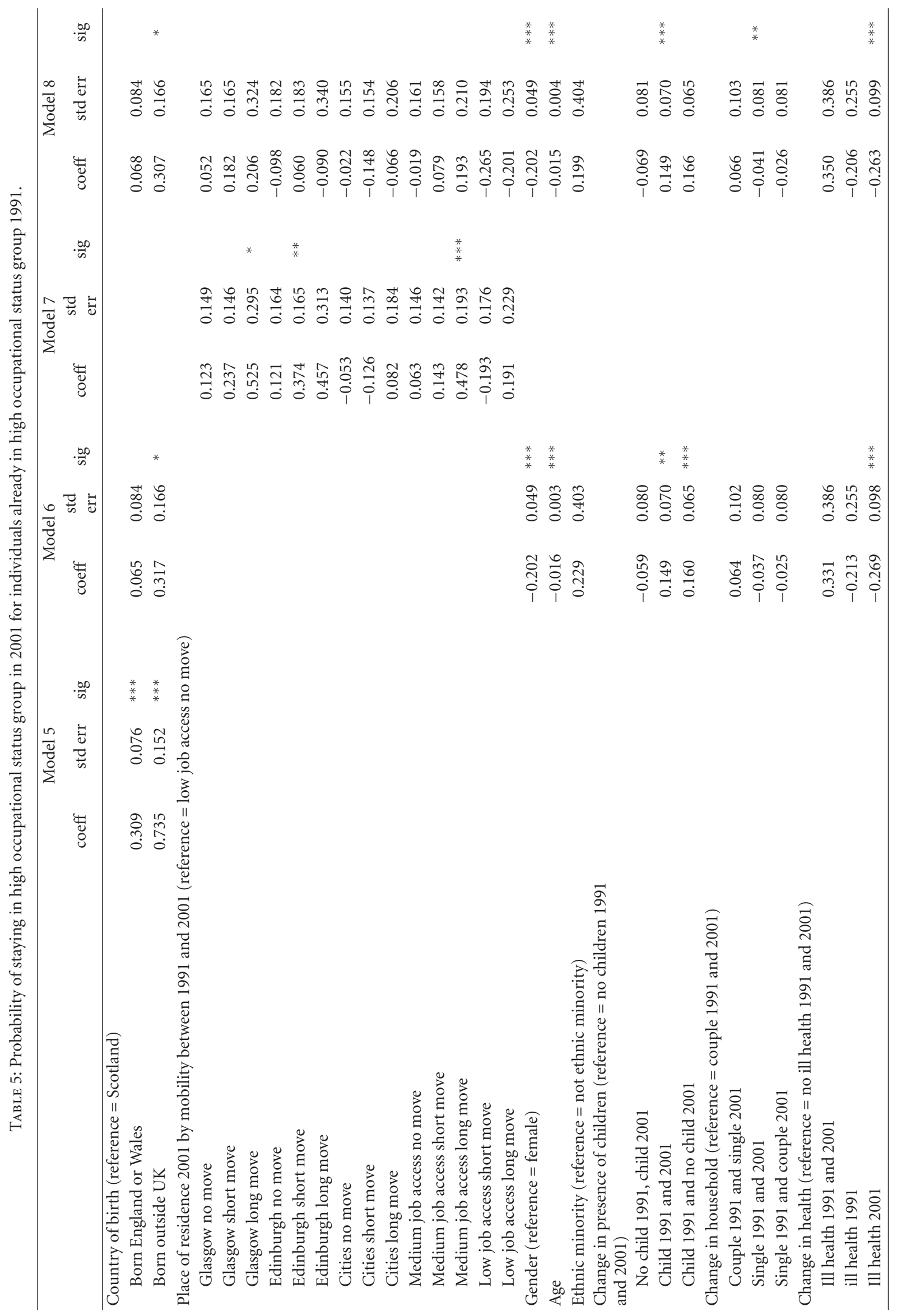




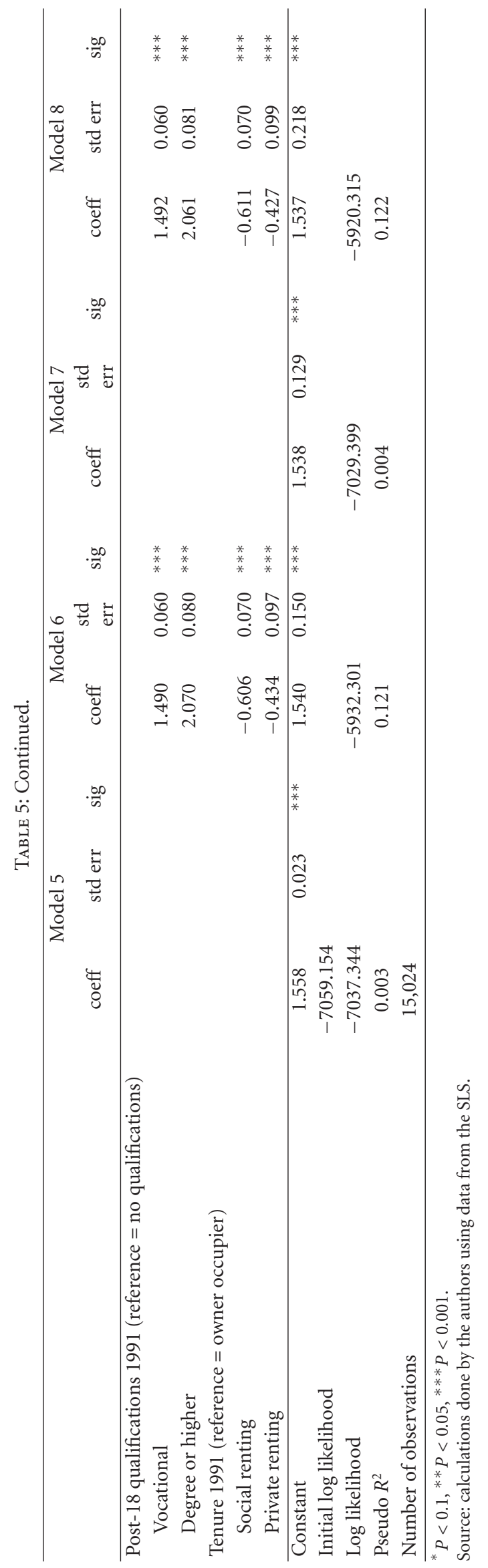


dividuals born in England, Wales, or outside Great Britain who have migrated to Scotland are likely to exhibit other characteristics associated with occupational mobility that are not included in our models, such as greater ambition or a greater willingness to take risks [36].

Model 2 also shows that females are (slightly) more likely to experience upward occupational mobility than males. This might seem surprising at first, but it is important to remember that our models include only females who were in employment in both 1991 and 2001, and these females are likely to be career orientated. As expected, increasing age reduces the probability of experiencing upward occupational mobility [37]. Belonging to a visible ethnic minority has a large negative impact on the probability of upward occupational mobility $[38,39]$. This highlights that there are significant and substantial barriers for upward occupational mobility for individuals in visible ethnic minorities.

Those living in a household which gained children between 1991 and 2001 are less likely to experience occupational mobility than those in a household with children in both years or those in a continuously childless household. Changes in household status do not seem to influence occupational mobility. Poor health, defined as having a limiting long-term illness, reduces the probability of experiencing upward mobility compared to good health, except when people suffered from poor health in both years. The most likely explanation is that those with continuously poor health, but with a job in both years, have adapted successful strategies promoting occupational mobility. The final individual level control variable in model 2 is housing tenure. Social renters in 1991 are the least likely to experience upward occupational mobility between 1991 and 2001, followed by private renters. Home owners are the most likely to experience upward occupational mobility, which can most likely partly be attributed to reverse causality.

Model 3 includes the place of residence in 2001 combined with the 1991-2001 migration status without any other control variables. The results clearly show that for all five places of residence, those individuals who have moved over a long distance are the most likely to have also experienced upward occupational mobility. Those individuals who have moved over a short distance are more likely to experience upward occupational mobility than those individuals who have not moved at all. It is important to note here that it is not possible to establish whether these are causal effects as we are not able to establish the order of the mobility event and the occupational mobility event. Nevertheless, the results are as expected (e.g., see [8]). Model 3 also shows clear evidence of escalator effects for Edinburgh, and to a lesser extent for Glasgow. Those individuals making long distance moves into Edinburgh are the most likely to experience upward occupational mobility, followed by those who make long distance moves into Glasgow. Individuals making short distance moves in and around Edinburgh are almost as likely to experience upward occupational mobility as individuals who make long distance moves into other cities, or within and into areas with good job access within 30 minutes.

Model 4 combines all variables from models 2 and 3 to include both individual and place of residence and migration characteristics. The coefficients for the individual characteristics remain similar to those in model 2. There are slight reductions in the magnitude of the coefficients for education, but these remain the most important determinants of individual upward occupational mobility. The place of residence and mobility coefficients are also smaller in model 4 compared to model 3, but the results are broadly the same. In all area of residence types, those individuals who made long distance moves are still the most likely to experience upward occupational mobility, with those individuals entering Edinburgh, Glasgow, or other cities experiencing the greatest advantage. The model clearly shows that Edinburgh functions as an escalator region within the Scottish context.

4.3. Retaining a High Status Occupation. Next, we look at the factors that contribute to maintaining a high occupational status between 1991 and 2001. We estimated the probability that those who were in the high occupational status group in 1991 were also in the high status group in 2001. Model 5 in Table 5 shows that without any control variables added to the model, those born in England and Wales, and especially those born outside Great Britain, are more likely to retain their high occupational status than those born in Scotland. In model 6, we add a range of individual level control variables. As a result, the country of birth variables loses much of its significance. Only those born outside the UK are slightly (at the $90 \%$ level) more likely to maintain their occupational position than the Scottish born reference group.

Many of the coefficients of the control variables are not significant. The gender variable shows that females are significantly less likely to keep their high occupational status than males. With increasing age, people are less likely to maintain their high status. There is no significant effect of belonging to a visible ethnic minority group, which indicates that members of this group are as likely to maintain their position as the rest of the population. So, although substantial barriers exist for ethnic minorities in terms of achieving higher status, there is no evidence that for the selected group that do achieve upward mobility there is further discrimination in terms of keeping these positions. People with children in both years, or only in 1991, are slightly more likely to maintain a high status compared to those without children. Individuals with ill health in 2001 are less likely to hold their high occupational status than the other health categories. As with gaining upward mobility, post-18 qualifications are very important in maintaining a high occupational status, especially a higher degree. Finally, private renters, and especially social renters, are less likely to hold on to their high occupational status than home owners.

In model 7, we included the combined place of residence in 2001 and migration status variable, but no other control variables. Only those individuals who made long distance moves to Glasgow and areas with medium job access within 30 minutes and those who made short distance moves into Edinburgh are more likely than the reference category (individuals not moving and living in areas with low job access within 30 minutes) to maintain their high occupational status. The final model, model 8 , combines all the variables from models 6 and 7. Those born outside Great Britain are 
still slightly more likely to keep their occupational status. There are no significant effects of place of residence and migration status. This suggests that once you achieve a high occupational status, your subsequent mobility and place of residence are not determinants for keeping that position. Individual level characteristics, and especially education, are far more important.

\section{Conclusions}

Using a powerful longitudinal dataset, the Scottish Longitudinal Study, this paper examined two important conceptual dimensions of occupational mobility: the influence of migration on occupational mobility and the potential for Scottish cities to act as escalators for individuals wishing to advance their occupational status.

Our analyses showed large regional differences in opportunities for occupational achievement in Scotland. They also showed that these can be overcome by investing in long distance moves; workers who move over long distances across Scotland are more likely than those who move over short distances and nonmovers to achieve upward occupational mobility. It is important to note here that long distance mobility does not cause upward occupational mobility, but it is likely to be a facilitator for occupational mobility by enabling access to more job opportunities. The analyses also showed that those who have made long distance moves to Scotland before 1991 (those born in England and Wales or outside Great Britain) are more likely than those born in Scotland to achieve upward mobility. The regional inequalities in job access and opportunities for occupational achievement are a worrying feature of the Scottish labour market. But this study also showed that those who are willing to take risk and move over long distances will benefit. The instrumental effect of long distance mobility does create uneven occupational mobility outcomes between Scots and elite migrants from outside the country who belong to the managerial capitalist class [25].

The most important finding is that Edinburgh and, to a much lesser extent, Glasgow operate as escalator cities in Scotland. Individuals moving to these two cities are more likely to experience upward occupational mobility than individuals moving to other parts of Scotland. The effect on occupational mobility of a long distance move to Edinburgh is almost similar in size as the effect of having a degree or higher. Edinburgh in particular, as the capital of a devolved nation and head office location for many financial services and regional public sector bodies, provides good opportunities for rapid social and occupational mobility. There is also a positive effect for individuals already living in Edinburgh or Glasgow, with those individuals who have not moved between 1991 and 2001 still being more likely to achieve upward mobility than other nonmovers in Scotland. This is an important finding as it indicates that there is a real benefit of working in these cities, and that the found escalator effects on occupational mobility are not just a result of more ambitious people moving to these cities (see also [7]). It is important to note that we found no association between spatial mobility and place of residence and keeping a high occupational status.

Of course the interpretation of our findings can be criticised. We acknowledge that with our data, it is not possible to establish to what extent the associations found between spatial mobility and occupational status mobility are causal effects as we are not able to establish the order of the mobility event and the occupational mobility event. Also, our data does not include any information on how long people have lived in their place of residence as observed in 1991 and 2001. The UK census only records place of residence every 10 years, and no information is available on the years in between the census days. Currently, no data is available for Scotland which would allows more detailed analyses of the ordering of spatial mobility and occupational status for a large set of origins and destinations. Also, we have to acknowledge that selection effects will be partly responsible for the effects of long distance mobility and escalator effects. As mentioned before in this paper, those who are more motivated to do well in their labour career are also more likely to move over longer distances. However, even in the context of these selection effects, the argument that long distance migration is instrumental in giving people access to more job opportunities still holds.

The main contribution of this study is that it is amongst the first to show that escalator effects $[1,2]$ are to be found outside major world city regions. We found that on a regional level, there are clear spatial inequalities in opportunities for occupational mobility from low occupational status jobs to higher occupational status jobs. We also found that moving to regional capitals has a positive association with occupational mobility. This finding might have relevance for other regional capitals in the world. The generality of regional escalator effects should be investigated further in different national and regional contexts. Newbold and Brown [4] recently suggested for Canada that regional escalator effects might only work for particular occupations in particular cities because some cities have a very specialised occupational structure. More insight into regional occupational structures and their effects on occupational mobility will increase our understanding of individual careers and the functioning of regional economies.

\section{Acknowledgments}

The help provided by staff of the Longitudinal Studies Centre-Scotland (LSCS) is acknowledged. The LSCS is supported by the ESRC/JISC, the Scottish Funding Council, the Chief Scientist's Office, and the Scottish Executive. The authors alone are responsible for the interpretation of the data. census output is Crown copyright and is reproduced with the permission of the Controller of HMSO and the Queen's Printer for Scotland.

\section{References}

[1] A. J. Fielding, "Migration and social mobility: South East England as an escalator region," Regional Studies, vol. 26, no. 1, pp. 1-15, 1992. 
[2] A. J. Fielding, "Migration and the metropolis: an empirical and theoretical analysis of inter-regional migration to and from South East England," Progress in Planning, vol. 39, no. 2, pp. 75-166, 1993.

[3] A. J. Fielding, "Class and space: social segregation in Japanese cities," Transactions of the Institute of British Geographers, vol. 29, no. 1, pp. 64-84, 2004.

[4] K. B. Newbold and W. M. Brown, "Testing and extending the escalator hypothesis: does the pattern of post-migration income gains in Toronto suggest productivity and/or learning effects?" Urban Studies, vol. 49, no. 15, pp. 3447-3465, 2012.

[5] T. Champion, "Testing the return migration element of the 'escalator region' model: an analysis of migration into and out of south-east England, 1966-2001," Cambridge Journal of Regions, Economy and Society, vol. 5, no. 2, pp. 255-270, 2012.

[6] W. M. Brown and K. B. Newbold, Cities and Growth: Moving to Toronto-Income Gains associated with Large Metropolitan Labour Markets, Statstics Canada, Ottawa, Canada, 4th edition, 2012.

[7] I. Gordon, "Ambition, human capital acquisition and the metropolitan escalator," Discussion Paper 107, SERC, 2012.

[8] M. van Ham, "Workplace mobility and occupational achievement," International Journal of Population Geography, vol. 7, no. 4, pp. 295-306, 2001.

[9] P. J. Boyle, P. Feijten, Z. Feng et al., "Cohort profile: the Scottish Longitudinal Study (SLS)," International Journal of Epidemiology, vol. 38, no. 2, pp. 385-392, 2009.

[10] P. M. Blau and O. D. Duncan, The American Occupational Structure, Wiley, New York, NY, USA, 1967.

[11] P. Krugman, The Age of Diminished Expectations, MIT Press, Cambridge, Mass, USA, 1994.

[12] P. Krugman, "Europe jobless: America penniless," Foreign Policy, 1994.

[13] D. Massey, Spatial Divisions of Labour, Macmillan, Basingstoke, UK, 1984.

[14] H. Bloetvogel and A. J. Fielding, Eds., People, Jobs and Mobility in the New Europe, Wiley, Chichester, UK, 1997.

[15] R. Lee, "Integration," in The Dictionary of Human Geography, R. J. Johnston, D. Gregory, G. Pratt, and M. Watts, Eds., pp. 398-402, Blackwell, Oxford, UK, 2000.

[16] M. Dunford and A. Fielding, "Greater London, the South-East region and the wider Britain," in People, Jobs and Mobility in the New Europe: Metropolitan Polarisation, Uneven Development and Inter-Regional Migration, H. Blotevogel and A. Fielding, Eds., pp. 247-276, Wiley, Chichester, UK, 1997.

[17] R. L. Martin, "Local labour markets: their nature, performance and regulation," in Handbook of Economic Geography, G. L. Clark, M. Feldman, and M. Gertler, Eds., pp. 455-476, Oxford University Press, Oxford, UK, 2000.

[18] C. H. Mulder and M. van Ham, "Migration histories and occupational achievement," Population, Space and Place, vol. 11, no. 3, pp. 173-186, 2005.

[19] A. Helderman, M. van Ham, and C. H. Mulder, "Migration and homeownership," Journal of Economic and Social Geography, vol. 97, no. 2, pp. 107-121, 2006.

[20] M. van Ham and P. Hooimeijer, "Regional differences in spatial flexibility: long commutes and job related migration intentions in The Netherlands," Applied Spatial Analysis and Policy, vol. 2, no. 2, pp. 129-146, 2009.

[21] E. de Meester and M. van Ham, "Symmetry and asymmetry in working and commuting arrangements between partners in the Netherlands: does the residential context matter?" Environment and Planning A, vol. 41, no. 9, pp. 2181-2200, 2009.
[22] M. van Ham, "Workplace mobility and occupational achievement," International Journal of Population Geography, vol. 7, no. 4, pp. 295-306, 2001.

[23] T. Champion, "Testing the return migration element of the "escalator region" model," in Proceedings of the Census Launch Conference, London School of Hygiene and Tropical Medicine, September 2004.

[24] A. Findlay, C. Mason, D. Houston, D. McCollum, and R. Harrison, "Escalators, elevators and travelators: the occupational mobility of migrants to South-East England," Journal of Ethnic and Migration Studies, vol. 35, no. 6, pp. 861-879, 2009.

[25] L. Sklair, The Transnational Capitalist Class, Blackwell, Oxford, UK, 2001.

[26] D. Conradson and A. Latham, "Friendship, networks and transnationality in a world city: antipodean transmigrants in London," Journal of Ethnic and Migration Studies, vol. 31, no. 2, pp. 287-305, 2005.

[27] A. Favell, Eurostars and Eurocities, Blackwell, Oxford, UK, 2008.

[28] A. M. Findlay, A. Stockdale, C. Hoy, and C. Higgins, "The structuring of service-class migration: english migration to Scottish cities," Urban Studies, vol. 40, no. 10, pp. 2067-2081, 2003.

[29] J. Webb, "Work and the new public service class?" Sociology, vol. 33, no. 4, pp. 747-766, 1999.

[30] M. Castells, The Rise of Network Society, Blackwell, Oxford, UK, 2nd edition, 2000.

[31] Office for National Statistics, Standard Occupational Classification 2000, Vol. 1. Structure and Description of Unit Groups, The Stationary Office, London, UK, 2000.

[32] Office for National Statistics, Standard Occupational Classification 2000, Vol. 2. The Coding Index, The Stationary Office, London, UK, 2000.

[33] Scottish Executive, "Scottish executive urban rural classification 2003-2004," 2004, http://www.scotland.gov.uk/.

[34] M. van Ham, P. Hooimeijer, and C. H. Mulder, "Urban form and job access: disparate realities in the Randstad," Journal of Economic and Social Geography, vol. 92, no. 2, pp. 231-246, 2001.

[35] A. C. Helderman, C. H. Mulder, and M. van Ham, "The changing effect of home ownership on residential mobility in the Netherlands, 1980-98," Housing Studies, vol. 19, no. 4, pp. 601-616, 2004.

[36] G. L. Coté, "Socio-economic attainment, regional disparities, and internal migration," European Sociological Review, vol. 13, no. 1, pp. 55-77, 1997.

[37] M. van Ham and F. Büchel, "Unwilling or unable? Spatial and socio-economic restrictions on females' labour market access," Regional Studies, vol. 40, no. 3, pp. 345-357, 2006.

[38] V. Robinson, "Roots to mobility: the social mobility of Britain's black population, 1971-87," Ethnic and Racial Studies, vol. 13, no. 2, pp. 274-286, 1990.

[39] L. Platt, Migration and Social Mobility, Policy Press, Bristol, UK, 2005. 


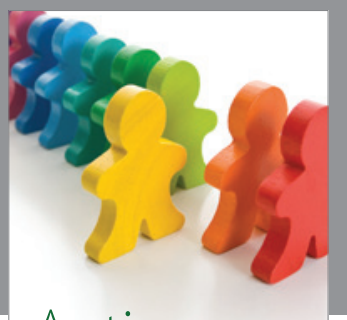

Autism

Research and Treatment
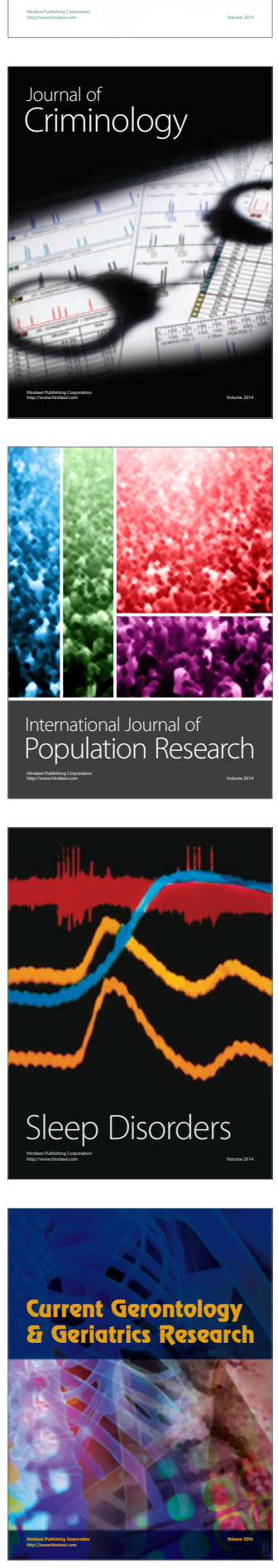
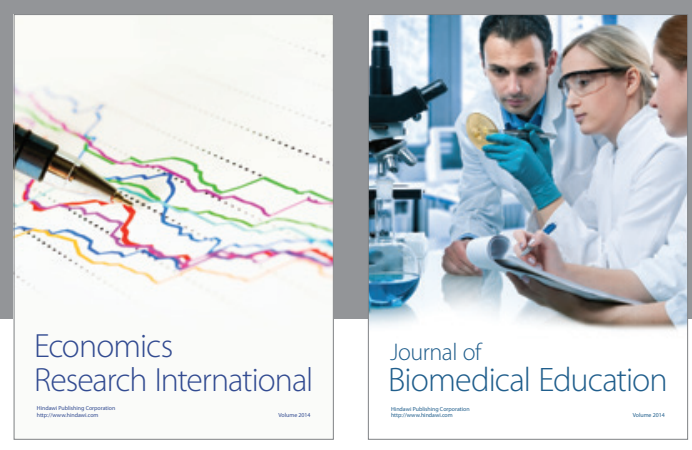

Journal of

Biomedical Education

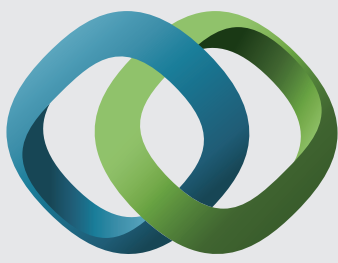

\section{Hindawi}

Submit your manuscripts at

http://www.hindawi.com
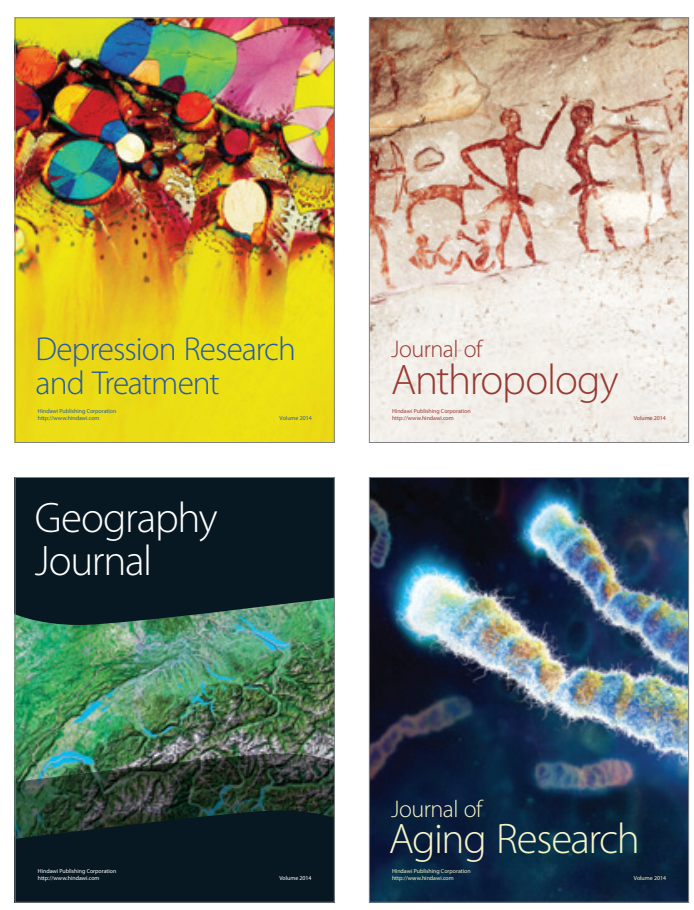

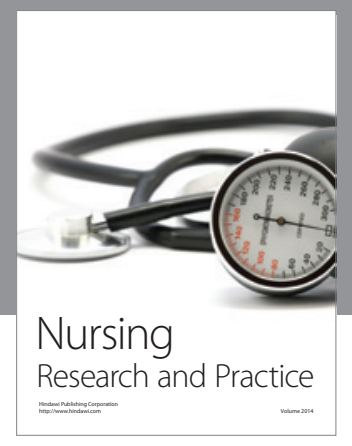

Nursing

Research and Practice

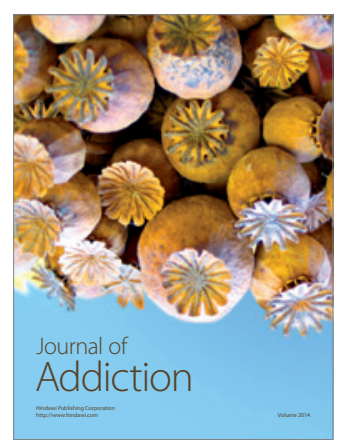

Child Development

Research

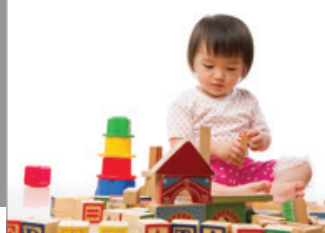

迥
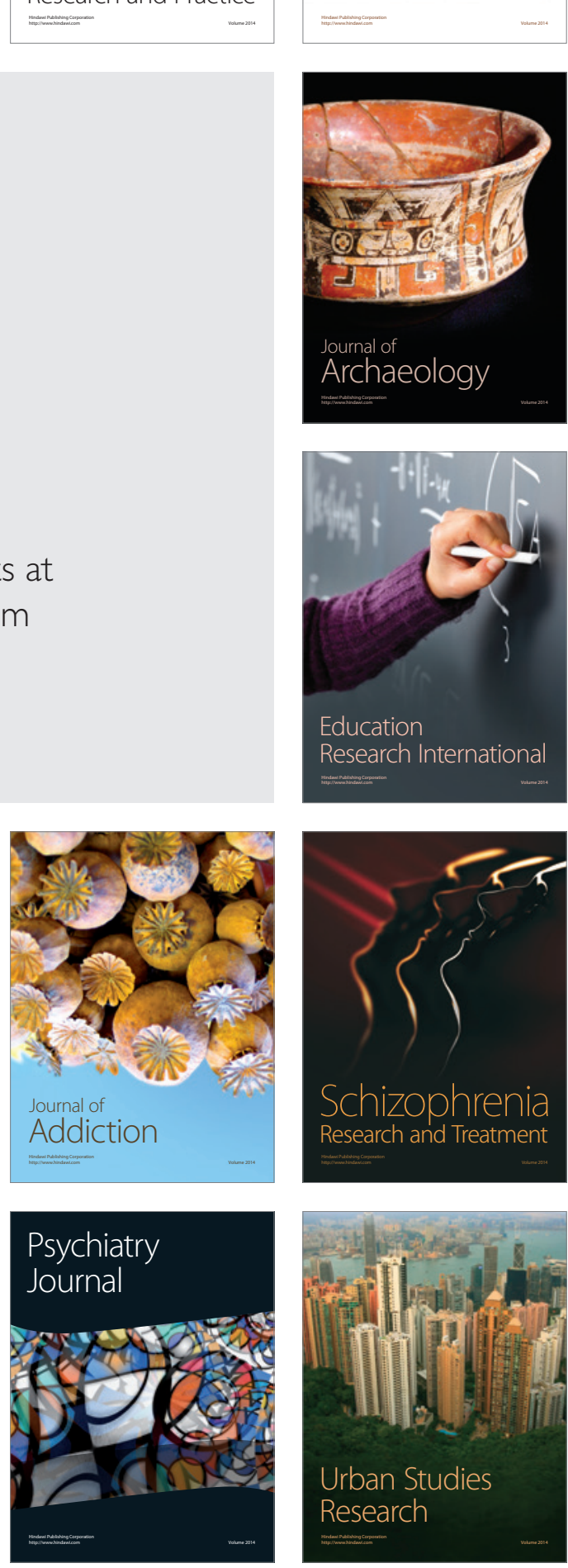